\title{
Giant obstructive myxoma presenting as mitral valve obstruction with severe pulmonary hypertension
}

\author{
Adama Sawadogo ${ }^{1^{*}}$, Yacouba Tamboura ${ }^{2}$, Modibo Doumbia $^{3}$, Ibrahima Baba Diarra ${ }^{3}$
}

${ }^{1}$ Department of Cardiovascular Surgery, University hospital of Clermont-Ferrand, France
${ }^{2}$ Department of Thoracic and Cardiovascular Surgery, University hospital of Fann, Senegal
${ }^{3}$ Department of Thoracic and Cardiovascular Surgery, Luxembourg Hospital, Mali

Corresponding Author: Adama Sawadogo, MD

Department of Cardiovascular Surgery, University hospital of Clermont-Ferrand, PO Box: 69, 63003 Clermont-Ferrand. France.

Email: adamsaw2000@yahoo.fr

Cite this article as: Sawadogo A, Tamboura Y, Doumbia M et.al. Giant obstructive myxoma presenting as mitral valve obstruction with severe pulmonary hypertension. Nepalese Heart Journal 2018; 15(2): 43-44.

Received date: $12^{\text {th }}$ June 2018

Accepted date: $13^{\text {th }}$ September 2018

\begin{abstract}
Cardiac myxomas may have different clinical presentations that may expose the patient to sudden death due to obstruction of the left ventricle inflow. The authors report a case of 34 years old male who was diagnosed with left atrial myxoma that presented as mitral valve obstruction with severe pulmonary hypertension. He underwent emergent sternotomy under cardiopulmonary bypass and the myxoma was successfully removed. The postoperative course was uneventful.
\end{abstract}

Keywords: Dyspnea, mitral stenosis, myxoma, pulmonary hypertension.

\section{Introduction}

Cardiac myxoma can lead to obstruction, usually of mitral valve flow, requiring timely determination of severity and necessity for emergent surgical resection ${ }^{1}$. We present a case of obstructive left atrial myxoma that presented as mimicking severe mitral stenosis with severe pulmonary hypertension. It was surgically removed by emergent sternotomy.

\section{Case presentation}

Our patient was a 34 years old male patient with no previous cardiovascular history. He has been suffering from increasing dyspnea and anorexia for 3 months. Due to an acute chest pain and severe New York Heart Association (NYHA) class III dyspnea, he was admitted to cardiac intensive care unit (ICU). The clinical examination did not find any sign of chronic heart failure. $\mathrm{He}$ was cachectic with decreased body mass index (BMI) (19kg/ $\mathrm{m} 2$ ). Cardio-pulmonary auscultation revealed late diastolic flow murmur. Electrocardiogram (ECG) showed sinus rhythm and complete right bundle branch block. On the echocardiogram, the right cavities were dilated. Also, it revealed a giant heterogeneous mass of $75 \mathrm{~mm}$ in the left atrium with a thin peduncle on the septum (figure 1). This mass was collapsing the mitral valve that was obstructed (figure 2) and it lead to severe pulmonary hypertension (pulmonary artery mean pressure (PAMP) 75 $\mathrm{mm} \mathrm{Hg}$ ). We concluded the diagnosis of obstructive left atrium myxoma and decided for urgent surgical ablation. The patient underwent sternotomy under cardiopulmonary bypass and bicaval cannulation. We used trans-septal approach: right atriotomy, then opening of atrial septum. Resection of the implantation of the mass on the septum was done and then it was removed from the left atrium (figure 3 ). The mitral valve was anatomically normal. The postoperative course was uneventful. On day 6 , the repeat echocardiogram showed a mild mitral regurgitation and partial recovery from the pulmonary hypertension (PAMP at $29 \mathrm{~mm} \mathrm{Hg}$ ). He was discharged from hospital on the day 7 postoperatively.

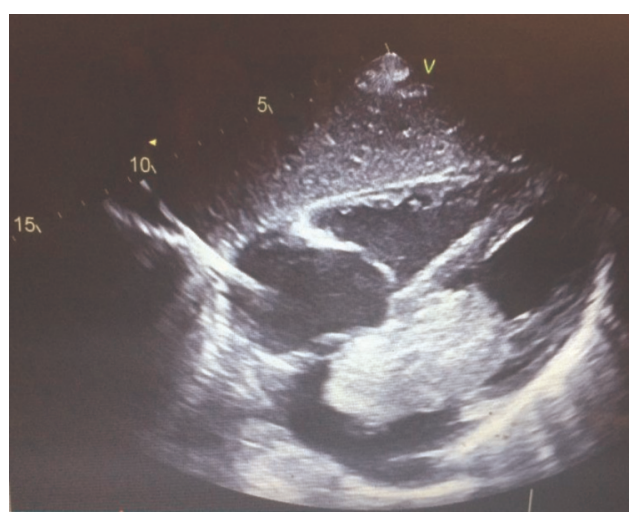

Figure 1: TTE 4-chamber view showing a mass protruding into the mitral valve

@Nepalese Heart Journal. Nepalese Heart Journal retains copyright and work is simultaneously licensed under Creative Commons Attribution License CC - BY 4.0 that allows others to share the work with an acknowledgement of the work's authorship and initial publication in this journal.

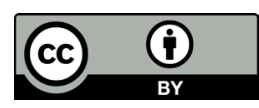




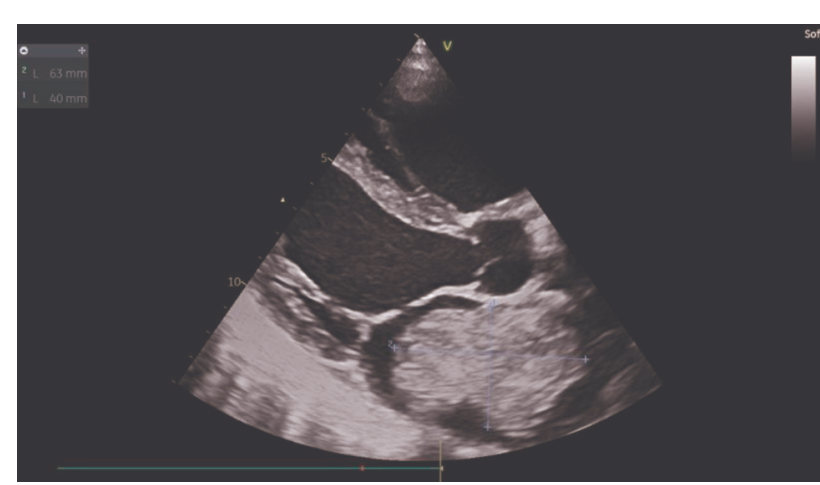

Fig 2: TTE parasternal long axis view showing the giant mass inside the left atrium

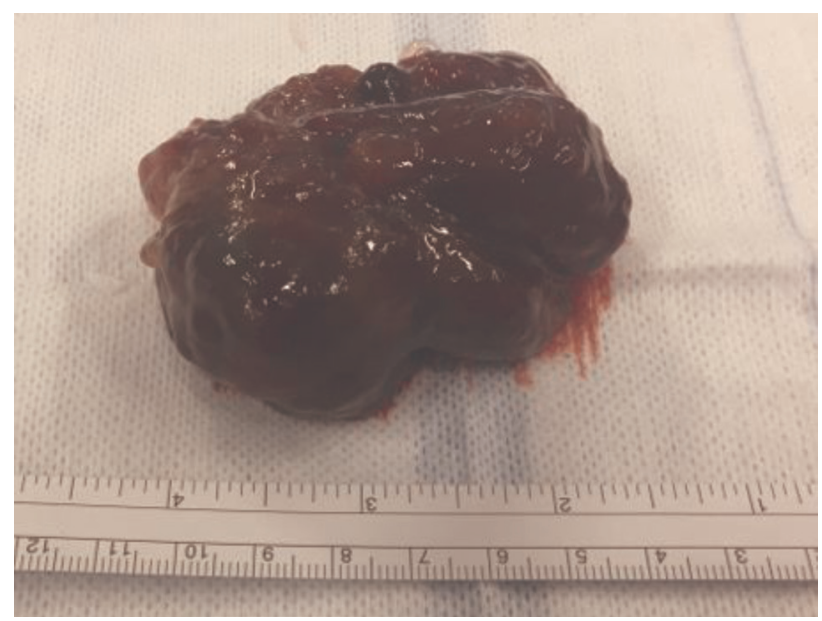

Fig 3: polypoid myxoma specimen after surgery

\section{Discussion}

Myxomas occur in all age groups, most frequently between the third and sixth decades of $\operatorname{life}^{2}$. About $75 \%$ of myxomas develop in the left atrium in both children and adults ${ }^{3}$. Although, it is a histologically benign disease, recurrence can occur most likely in about $3 \%$ of patients, which is higher in familial cases as compared to sporadic cases ${ }^{4}$. Depending on the size and location of the myxoma, patients can be asymptomatic or exhibit various degrees and types of cardiac insufficiency ${ }^{2}$. Typically, atrial myxomas protrude into and obstruct the atrioventricular valves and can cause syncopal episodes and sudden death ${ }^{5}$.
We decided to emergently perform surgery because of the risk of acute pulmonary edema. The diagnosis can be easily made by transthoracic echocardiogram but trans-esophageal echocardiogram appears to be helpful to determine the tumor location $^{5}$. In our case, due to the serious clinical features, we found meaningless to delay the surgery for any reason. That is why we did not wait to electively perform mini invasive approach that is possible in our Centre. Nevertheless, the postoperative course was satisfactory. Overall, the rapidity of the decision to surgically remove the obstructive myxoma saved the patient's life.

\section{Conclusion}

Mitral valve obstruction can be one of the presentations of left atrium myxomas that expose the patient to risk of sudden death. In this situation, approach by classical open surgery appears to be an efficient and affordable procedure to remove it. We hereby present the case to increase the awareness of the urgency of this disease and its emergency management.

\section{Conflict of interest}

The authors do not have any conflict of interest including financial in publication of this article.

\section{References}

1. Chen RJ, Chou HH, Tsai KT et.al. Cardiac myxoma with unusual obstructive and embolic presentations: concurrent stroke and angiography-negative myocardial infarction, a case report. Medicine 2015; 94(38):1602. https://doi.org/10.1097/MD.0000000000001602

2. Reynen K. Cardiac myxomas. N Engl J Med. 1995; 333(24):1610-7.

https://doi.org/10.1056/NEJM199512143332407

3. Reddy SN, Sunil GS, Kumar RK. Surgical removal of a left ventricular myxoma in an infant. Ann Pediatr Cardiol. 2013; 6:179-81. https://doi.org/10.4103/0974-2069.115276

4. Kumar S, Mangukia C, Singh H, Satsangi D. Biatrial multifocal recurrence of sporadic left atrial myxoma. Indian J Thorac Cardiovasc Surg. 2015;31(4):323-25. https://doi.org/10.1007/s12055-015-0395-0

5. Wiegand G, Sieverding L, Kramer U et.al. Multimodality imaging of a subtotally obstructive right ventricular myxoma in an asymptomatic 10-year-old girl. Ann Pediatr Cardiol. 2014; 7(2):158-9.

https://doi.org/10.4103/0974-2069.132519 